\title{
Modelling Reachability in Transport Networks: Using Alternative Visual Representations in Interactive Linked-Views to Gain Valuable Insights
}

\author{
Rehmat Ullah $\mathbb{D}^{1},{ }^{1}$ Laiq Hasan, ${ }^{1}$ Farman Ullah, ${ }^{2}$ Ajmal Khan, ${ }^{2}$ and You-Ze Cho ${ }^{3}{ }^{3}$ \\ ${ }^{1}$ Department of Computer Systems Engineering, University of Engineering and Technology Peshawar, Peshawar, Pakistan \\ ${ }^{2}$ Department of Electrical and Computer Engineering, COMSATS University Islamabad, Attock Campus, Attock, Pakistan \\ ${ }^{3}$ School of Electronic and Electrical Engineering, Kyungpook National University, Daegu 41566, Republic of Korea
}

Correspondence should be addressed to You-Ze Cho; yzcho@ee.knu.ac.kr

Received 29 July 2020; Revised 22 October 2020; Accepted 22 January 2021; Published 8 February 2021

Academic Editor: Juan Carlos Cano

Copyright (C) 2021 Rehmat Ullah et al. This is an open access article distributed under the Creative Commons Attribution License, which permits unrestricted use, distribution, and reproduction in any medium, provided the original work is properly cited.

Most people use maps for navigation. Geographic maps visually represent physical distance between locations. These maps sometimes provide a false impression of travel times. Two cities geographically close to each other might be "far apart" in terms of travel time because of slower connections, whereas two cities geographically distant might be "nearby" in terms of travel time because of faster connections. Under such circumstances, visualizing a transport network using time as a distance measure can make the transport network more understandable. This study integrates several (carto)graphic representations-a time line, a distance line, a time prism, a time cartogram, and a geographic map-in an interactive linked-views environment to model reachability in transport networks. A prototype is implemented in a web environment using D3.js. The implementation can be applied to any transport network. In this research, the approach is illustrated with railroad network data for the Dutch province of Overijssel. The solution provides an alternative and insightful perspective for analyzing the data. In addition to complementing a wide variety of methods to visualizing travel times, the approach could be applied in areas such as spatial analysis and transport planning.

\section{Introduction and Background}

Sources of geographical data are abundant, and its temporal component is often associated with change or movement. Movement can be continuous like wind and currents in the oceans or discrete having a clear origin and/or destination. This last type of movement can follow a fixed network, such as rail or road network, or be free like movement of animals. Due to the complexity of the data, there is a need for the development, application, and evaluation of interactive analytical cartographic representations in order to produce meaningful insights about the movement data and effectively support spatiotemporal inference and decision-making by people [1-3]. Of the many different available representations, most work very well with the locational and attribute component of data, whereas representations that also work with the data's temporal component have not been sufficiently developed $[4,5]$.

Most people use maps for navigation. When making a trip, travel time between two locations can in some cases be more important than physical distance between them. In geographic maps, however, travel time and distance do not correlate equally across the map. For instance, city A can be geographically close to city $\mathrm{B}$, while city $\mathrm{C}$ is rather distant from $\mathrm{B}$, but in terms of travel time, A might be farther apart than $C$ because of slower or longer connections. To make these insightful, different methods can be used to visualize travel times.

A table can be provided to show travel times. However, in such a case, a user loses the geographical context. On a map, labels can be used to display travel times along segments of roads, in which case a user has to read the 
individual labels to calculate travel times (see Figure 1(a)). Besides, labels take up space in the map and can make the map crowded because of a large number of labels. Another approach is to use labels at destinations only. In Figure 1(b), all stations reachable from Enschede have a label with the travel time needed to reach the particular station. A disadvantage of this solution is that it is only valid from a single location, here Enschede. In Figure 1(c), ten-minute isochrones have been drawn and time zones between the lines have been filled with color, applying the visual variable "value." The darker the zone is, the more time it takes to reach the zone. This has the same disadvantage as with labels at destinations (Figure 1(b)). An alternative approach is the use of time cartograms [6-9]. In a time cartogram, the geographic distance between locations is replaced by travel time. This potentially distorts the geography accordingly. This distortion can give a clearer picture of what is nearby or distant in terms of travel time (see Figure 1(d)). The distortion of the geography, however, can make the area of interest difficult to recognize $[8,10,11]$. Similar to the examples in Figures 1(b) and 1(c), this solution is also valid from a single location only. However, this may not be a problem in an interactive environment where the user can change the starting location. Alternative to distorting the base map, only network segments can be distorted, keeping the locations fixed (see $[12,13])$. However, the resulting maps from the transformation approach proposed by Buchin et al. [12] do not suit networks in which segments are dense and plenty because the curves might intersect, making the cartograms harder to read (see Figure 2(a)). Similarly, the resulting cartograms from the approach proposed by $\mathrm{Wu}$ and Hung [13] do not suit networks with long segments far away from each other or with irregular patterns (see Figure 2(b)). These observations made us look for other supplemental graphic representations to model reachability in transport networks.

For this purpose, we integrated several (carto)graphic representations - a time line, a distance line, a time prism, a time cartogram, and a geographic map-in an interactive linked-views environment (as shown in Figure 3). The departure time picker (labelled 1) indicates the time during the day. The picker can be moved back and forth to a particular time of the day. This will show the time of the first train leaving (e.g., 05:16 AM as indicated by 2). The geographic map (labelled 3) visualizes the railroad network and the spatial relationships of stations of the Dutch province of Overijssel. The travel origin or starting station (i.e., Enschede) is shown by a black square on the map and the other stations are represented by dots. The stations that are reachable at a selected time instant (here 05:16 AM) are colored green, and those that are not reachable are colored red. The map also shows both reachable and non-reachable subnetworks at a selected moment in time. The time cartogram (labelled 4) shows the reachable subnetwork from Enschede at a selected time instant. The concentric circles depict the travel times in steps of 10 minutes from Enschede to other destinations in the reachable network. The time line (labelled 5) shows the travel times in minutes from Enschede to only those stations that are reachable at a selected moment in time. The distance line (labelled 6) shows the physical distances, based on crow flies, in kilometers from Enschede to all stations. On both lines, the stations that are reachable at a selected time instant are colored green. The distance line also shows the stations that are not reachable in red.

The check box (indicated by 7) can be used to select one station to see how the reachability of the selected station changes over the day. A station can be selected by checking the check box and then clicking on the desired station in the geographic map. The time budget picker (labelled 8) can be used to choose a time budget (the time that one could spare to travel, excluding sightseeing). Label 9 displays the chosen time budget. An individual can travel from the starting station to all reachable stations (indicated on the time line) within the time budget. The stations dynamically appear or disappear on the time line as soon as the time budget is increased or decreased using the time budget picker. To better use and understand the network and explore patterns in space and time, we linked all the views in the visualization environment. For example, whenever one moves the mouse over a station in any of the views, the corresponding station is also highlighted in the other views (e.g., Ommen in Figure 4).

The visualization can also be animated. The animation runs from 12:00 AM to 11:59 PM to show how the reachability of stations changes over time. An animate/pause button is provided to run/pause the animation at any moment in time.

Reachability in time-geography theory is indicated by what Hägerstraand [14] referred to as the space-time prism. The space-time prism determines the ability of individuals to travel to different locations in a network in a limited interval of time. Later, several researchers have attempted to operationalize and apply the space-time prism in spatial analysis and planning (e.g., [15-19]). However, the full potential of the space-time prism has not been realized in locational analysis and transportation planning [20-22].

This research introduces a linear version of the space-time prism by mapping the transport network onto time and distance lines. The modified version is termed time prism. An example of the time prism can be seen in Figures 5 and 6 . Figure 5 shows the input network: the travel origin (i.e., Enschede) and all other stations are indicated. The stations that are reachable at the selected time instant are indicated by green dots, while the stations that are not reachable are indicated by red dots. The time line shows the travel times in minutes from Enschede to only those stations that are reachable. The distance line shows the physical distances in kilometers from Enschede to all stations. Figure 6 shows the network after the application of the prism with time budgets of 40 and 80 minutes, respectively. The time lines in both cases indicate the subnetworks that are reachable. One can travel from the origin to any station in the reachable subnetwork within the selected time budget. As evident, more stations can be reached when the time budget is increased from 40 minutes to 80 minutes (compare Figure 6(a) versus Figure 6(b)).

A prototype of the visualization system was implemented in a web environment using D3.js. The implementation can be applied to any transport network. In this 


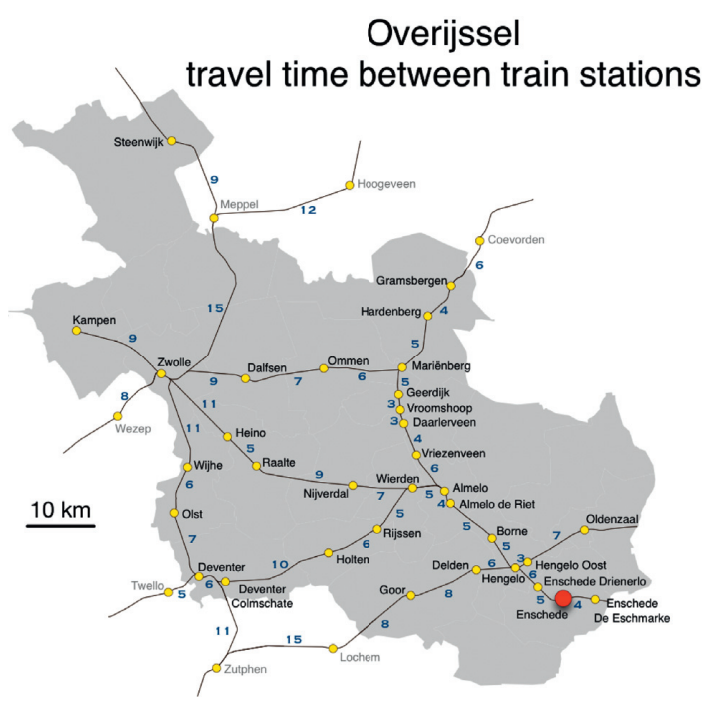

(a)

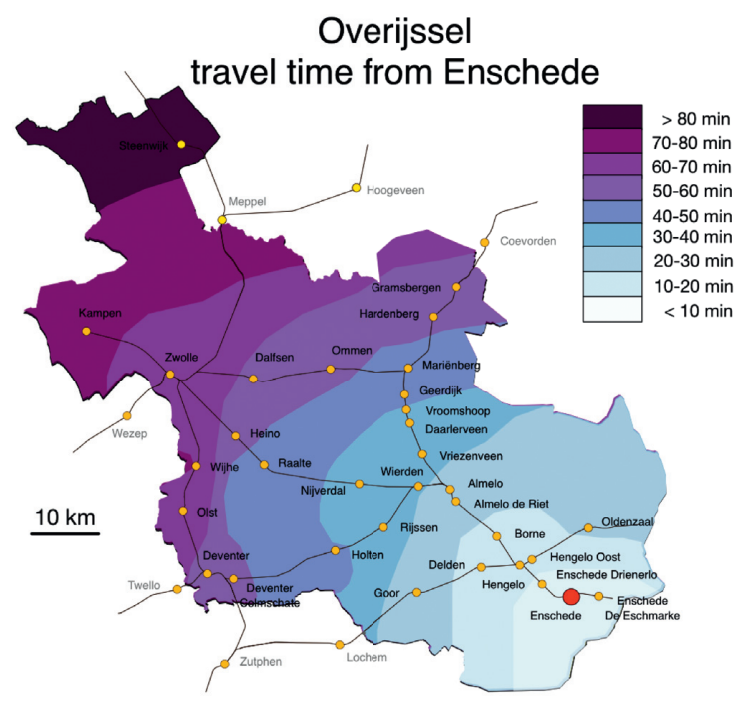

(c)
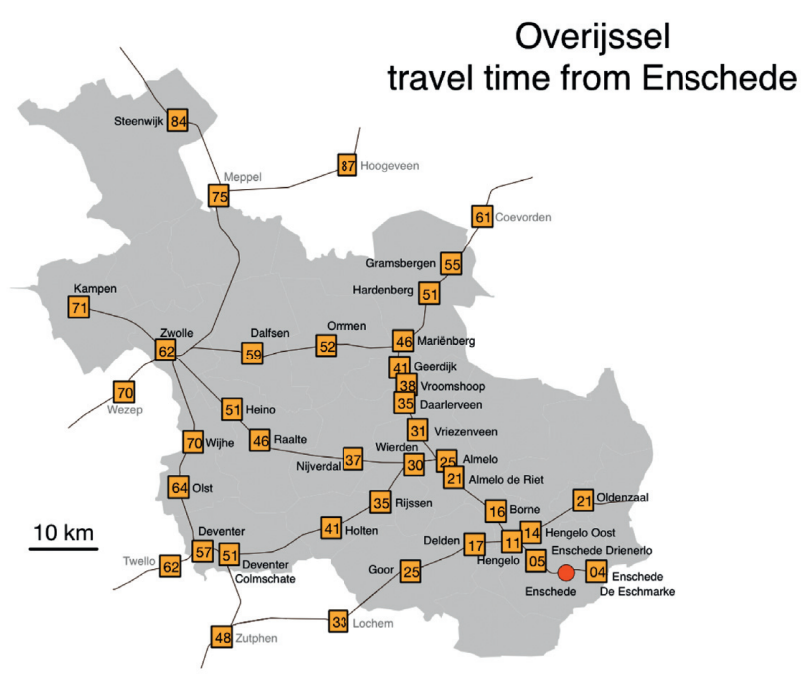

(b)

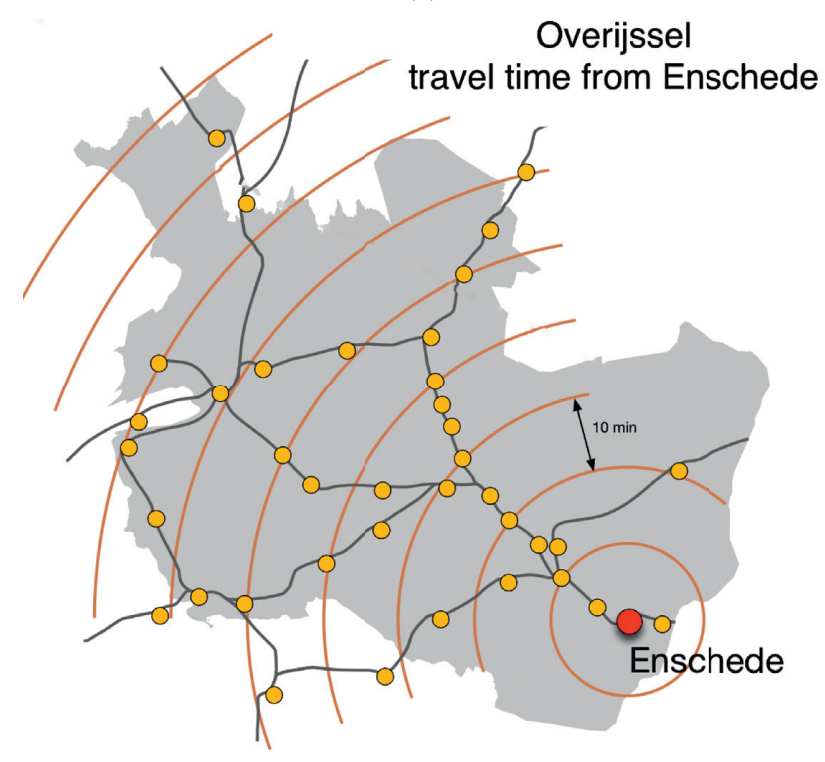

(d)

FIgUre 1: Mapping travel time by train from the city of Enschede to other towns in the Dutch province of Overijssel. (a) Labels along network segments. (b) Labels at destinations. (c) Isochrones. (d) A time cartogram [6].

study, the approach is illustrated with railroad network data for the Dutch province of Overijssel. Our solution provides an alternative and insightful perspective for analyzing the network. The proposed method solves the clutter and overplotting problems found in other representations, like the labelling. In addition to complementing a wide variety of methods to visualizing travel times, our approach could be applied in areas such as spatial analysis and transport planning. It can help transport planners to know how the reachability of stations changes over time and also to investigate which segments of the transport network are heavily-served and which are under-served. Using the visualization environment, the transport planners could figure out which stations take more time to reach despite the fact that they are geographically closer and could improve the connections if needed.
The remainder of this paper is organized as follows: Section 2 discusses the data used to illustrate the visualization and Section 3 explains the design and implementation of the visualization environment. In Section 4, we show how our visualization environment can be used to answer the user questions (listed in Table 1). Finally, in Section 5, we provide conclusions and look at possibilities for future work.

\section{Data}

A dataset of the railroad network of the Dutch province of Overijssel was used to illustrate the method. The dataset consists of the intercity and regular train stations and the trains' time tables plus an administrative map of the province. This network has 33 train stations and is shown in 


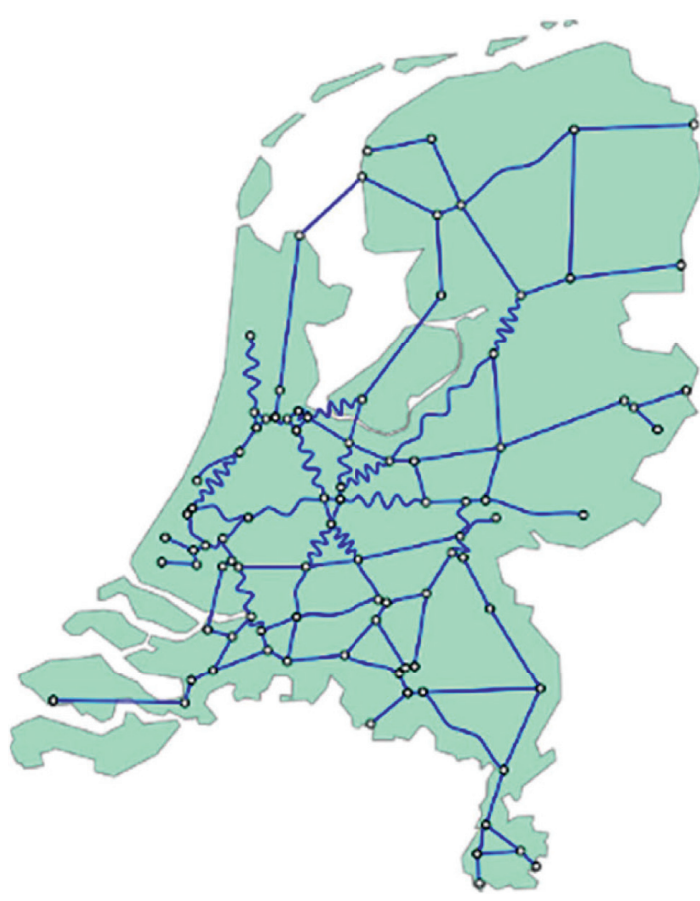

(a)

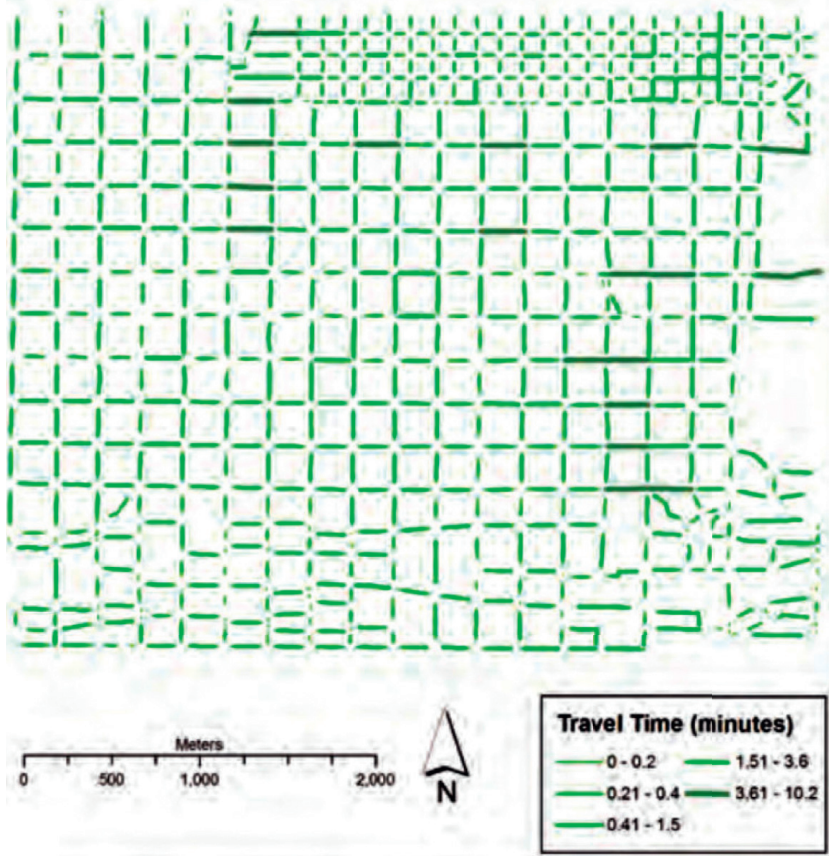

(b)

Figure 2: (a) A linear cartogram with fixed vertex locations showing travel times for the Dutch railroad network. The map and the locations are fixed, but edges are drawn as sinusoid curves to indicate travel times [12]. (b) A nonconnective linear cartogram showing travel times in Salt Lake City, Utah. Such cartograms do not show the connectivity between line segments. Lengths and widths of road segments are modified according to travel times [13].

Figure 1(a). We chose Enschede as the starting station. Both intercity and stop trains were considered to calculate the travel times from Enschede to all other destinations.

\section{Design and Implementation}

Unlike the present design approaches on visualizing travel times (e.g., $[6,7,9,12,13,23-31])$, the design and implementation of the proposed visualization environment were approached by using a systematic, user-centric, and taskoriented visualization design framework (see, e.g., [32-35]). In the first step, a set of user questions (listed in Table 1) were formulated in coordination with both frequent and casual train travelers. The travelers, from 25 different nationalities, were postgraduate students and staff members of the Faculty of Geo-Information Science and Earth Observation at the University of Twente in the Netherlands. For details on this study, see our article "Usability evaluation of centered time cartograms" in the June 2016 issue of the Journal of Open Geosciences. Questions 1 to 5 are typical travel time questions, while others are more analytical questions. The questions were chosen to be real-world, with the intention to assess the practical value of the visualization approach. In the second step, the design and implementation of the visualization environment (largely influenced by the user questions and users' ease in interacting with it) were carried out to answer the user questions.

No one single visualization can completely address all the above questions without suffering from clutter and overplotting $[35,36]$. These problems can partly be solved by combining different visual representations in an interactive linked-views environment [37]. In addition, the use of different interactive linked visual representations can be helpful in revealing patterns otherwise missed because they each provide their own unique perspective on the data $[4,38-40]$.

To implement the visualization, we used HTML5 for encoding web pages, CSS3 for styling and layout, SVG for vector graphics, and JavaScript for interaction and animation. Several JavaScript frameworks and libraries support Open Web Platform. We chose the D3 library [41]. D3.js is a JavaScript library for manipulating documents programmatically based on data. It allows binding arbitrary data to a Document Object Model (DOM) and then applying datadriven transformations to it. Its code structure, based on JavaScript framework jQuery, helps to produce dynamic and interactive data visualizations using the full capabilities of modern web standards such as HTML5, SVG, and CSS3 in modern web browsers [36]. Furthermore, D3 is fast and efficient, even for large datasets [42]. 


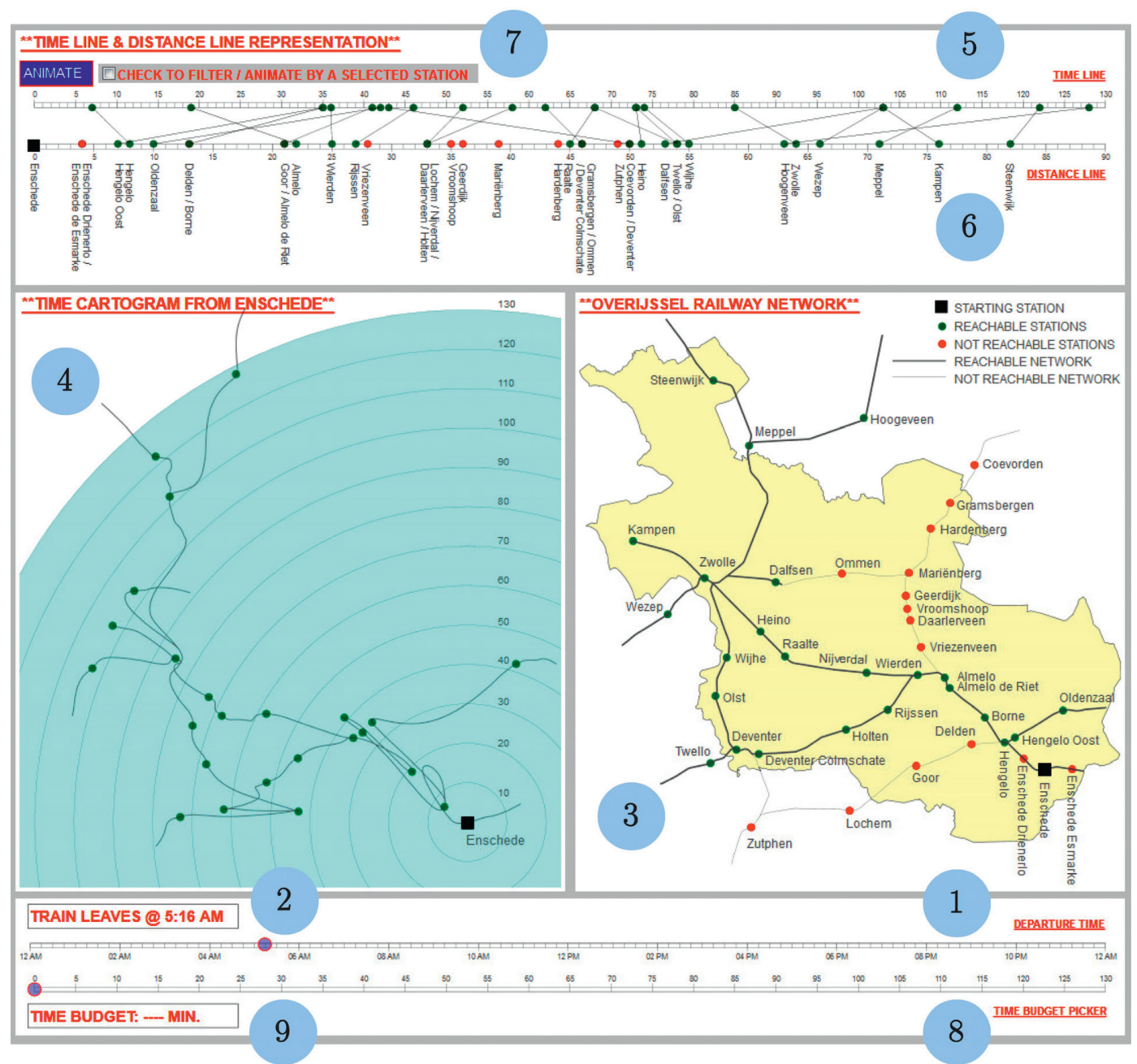

FIgURe 3: The visualization environment integrating the time line (labelled 5), the distance line (labelled 6), the time prism (labelled 1, 2, 5, 6, 8 , and 9), the geographic map (labelled 3), and the time cartogram (labelled 4). All views are interactive and linked: moving the mouse over a station in any of the views highlights the corresponding station in the other views.

\section{Working with the Visualization}

Figure 3 shows the different elements of the visualization environment and their functionalities. Below, we discuss how our visualization environment can be used to answer the posed user questions (see Table 1).

4.1. UQ1: How Long Does It Take to Reach Station X with the First Train Departing after Time T? Figure 4 shows how one can find the travel time to station $X$ with the first train departing after time $T$. Select the time instant on the time slider (e.g., 06:00 AM in Figure 4). The first train after the selected moment leaves at 06:04 AM. The time line and the time cartogram show the travel times of all the stations that are reachable from Enschede with the train leaving at 06:04 AM. The geographic map and the distance line show all the stations with the reachable stations in green and those not reachable in red. By selecting any reachable station in the map or time cartogram or on time line or distance line, one can see how much time is needed to reach the station. In
Figure 4, Ommen is selected. The time line and the time cartogram show that it takes 93 minutes to reach Ommen from Enschede with the train leaving at 06:04 AM. The distance line shows the physical distance from Enschede to Ommen (46 kilometers).

4.2. UQ2: Which Stations Are Reachable with the Train Departing at Time T? Clicking on the animate/pause button plays/stops the animation. The animation runs from 12:00 AM to 11:59 PM and shows how the reachability of stations changes over time. The time slider can also be moved forward and backward to interact with the animation. Figures 4 and 7 explain how an individual can know which stations are reachable with the train leaving at time $T$. Figure 4 shows all stations that are reachable with the train departing at 06:04 AM, while Figure 7 shows all stations that are reachable at 06:16 AM. The reachable stations are colored green, whereas those not reachable are colored red. One can see that fewer stations are reachable with the train departing at 06:16 AM than at 06:04 AM. 


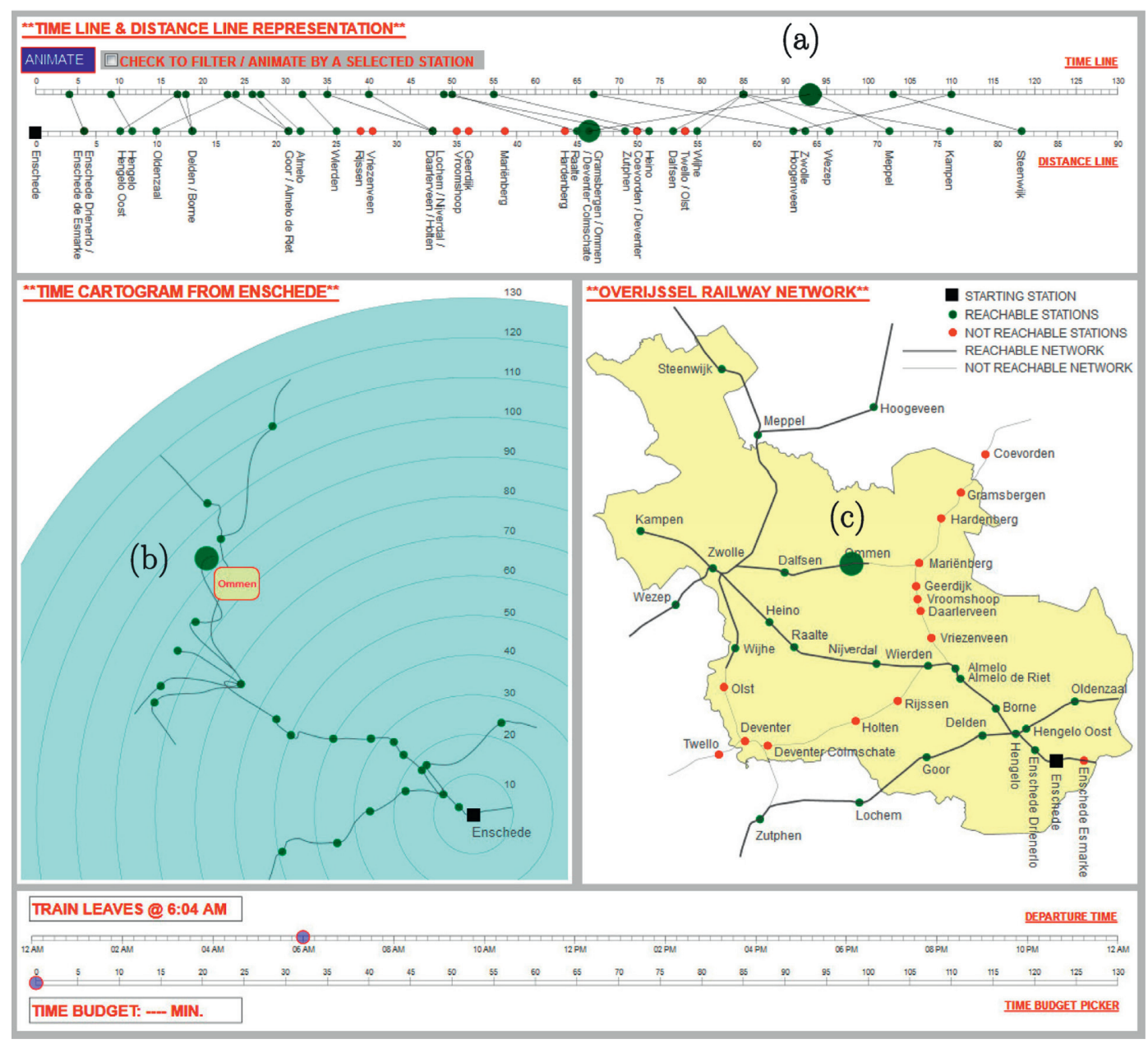

FIGURE 4: Travelling from Enschede with the train departing at 06:04 AM. The reachable stations are indicated by green dots, whereas those not reachable are indicated by red dots. The time line (a) and the time cartogram (b) show that it takes 93 minutes to reach the highlighted station (Ommen) from Enschede when leaving at 06:04 AM.

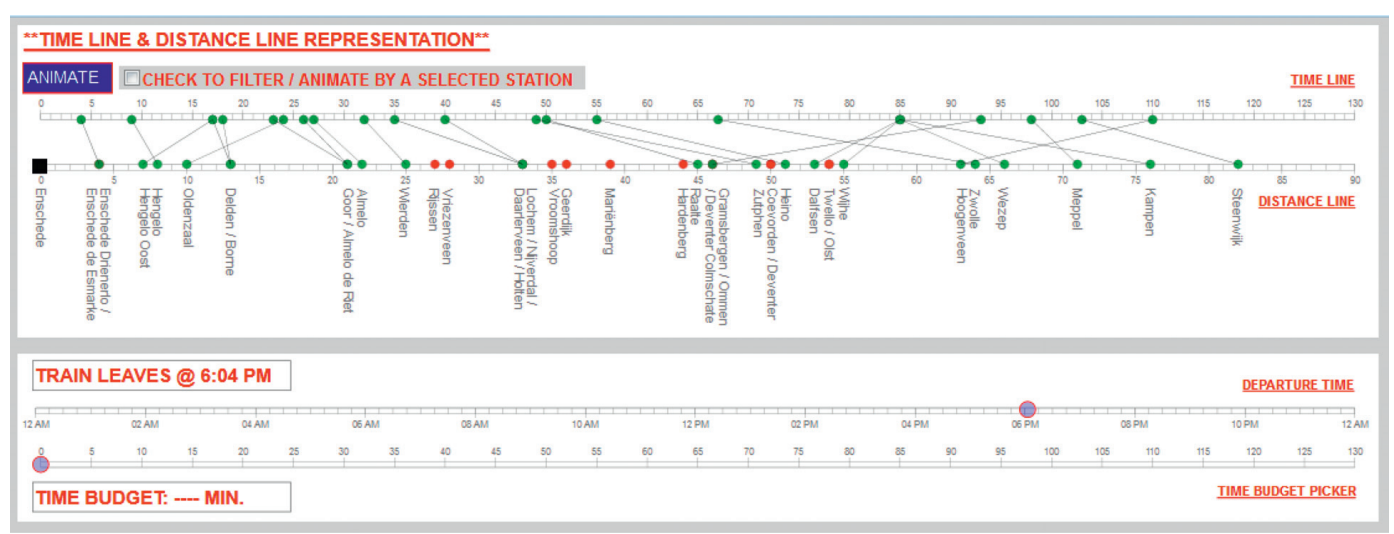

Figure 5: Travelling from Enschede with the train departing at 06:04 PM with no time budget constraints. The reachable stations at the selected moment in time are indicated by green dots, while the non-reachable stations are indicated by red dots. The time line shows the travel times in minutes from Enschede to only those stations that are reachable. The distance line shows the physical distances in kilometers from Enschede to all stations. 


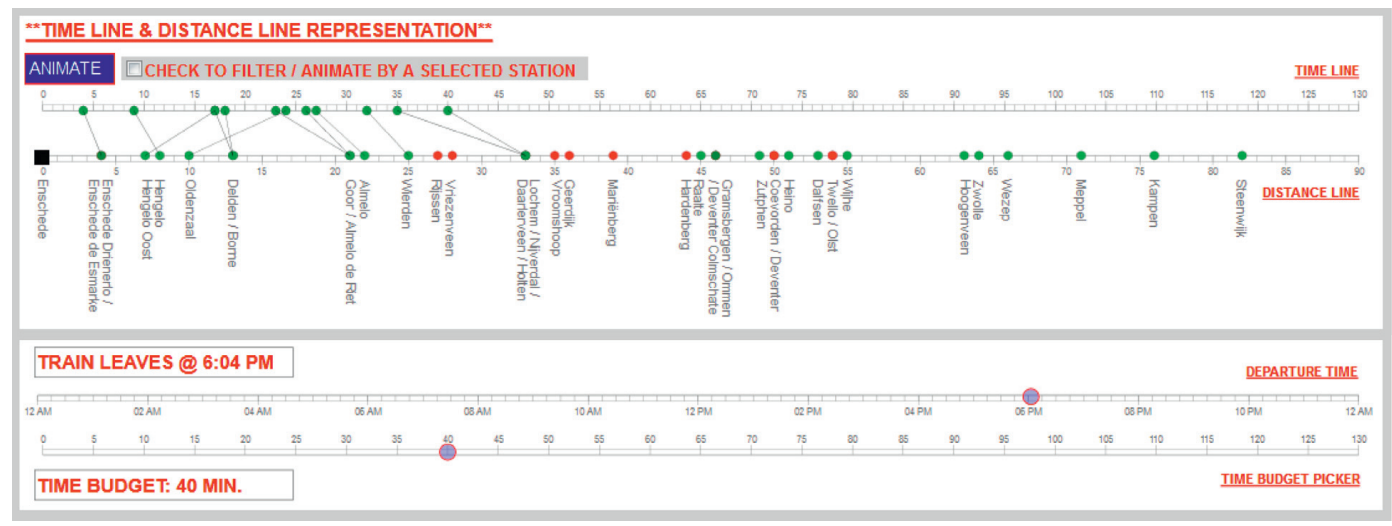

(a)

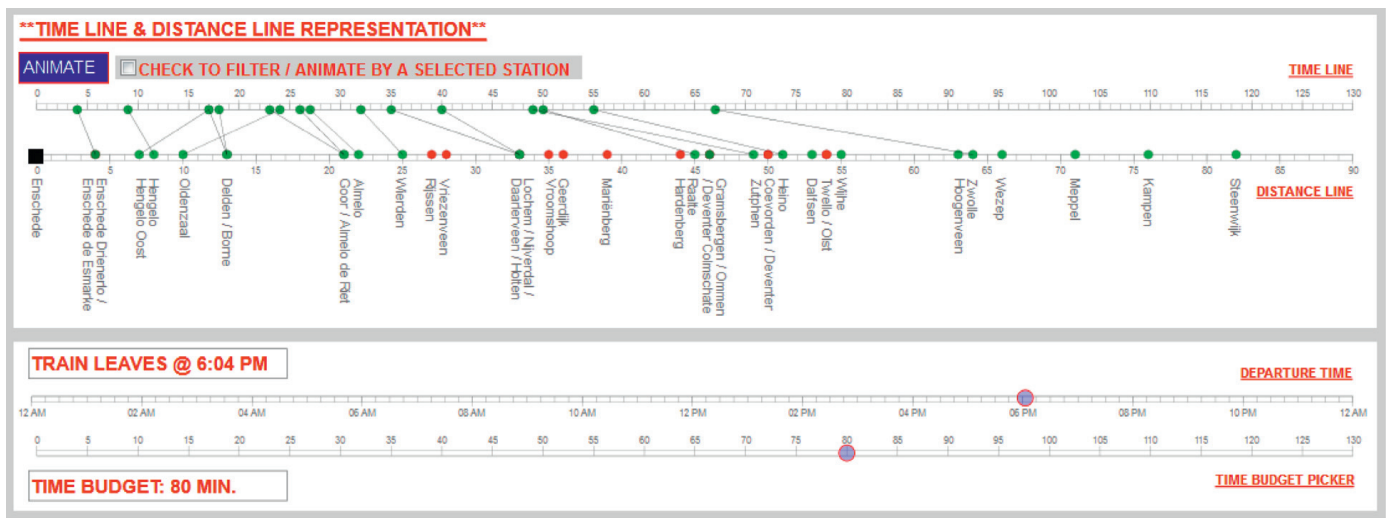

(b)

Figure 6: An example of the time prism showing the reachable subnetworks from Enschede with the train departing at 06:04 PM after the application of prism with time budgets of (a) 40 minutes and (b) 80 minutes.

TABLE 1: List of user questions.

\begin{tabular}{|c|c|}
\hline & User Questions \\
\hline UQ1 & $\begin{array}{l}\text { How long does it take to reach station } X \text { with the first train departing after time } T \text { ? } \\
\text { Example: How long does it take to reach Ommen with the first train departing after 06:00 AM? }\end{array}$ \\
\hline UQ2 & $\begin{array}{l}\text { Which stations are reachable with the train departing at time T? } \\
\text { Example: Which stations are reachable with the train departing at 06:04 AM? }\end{array}$ \\
\hline UQ3 & $\begin{array}{l}\text { Which stations can be reached within } X \text { minutes with the train departing at time } T \text { ? } \\
\text { Example: List all stations reachable within } 60 \text { minutes with the train departing at 06:04 AM. }\end{array}$ \\
\hline UQ4 & $\begin{array}{l}\text { When does it take the least or the most time to reach station } X \text { during time interval T1-T2? } \\
\text { Example: When does it take the least or the most time to reach Ommen between 06:00 AM and 07:00 AM? }\end{array}$ \\
\hline UQ5 & $\begin{array}{c}\text { Given a time budget of X minutes, which stations can be reached with the first train departing after time T? } \\
\text { Example: Robert is in Enschede to attend a 3-day workshop at the University of Twente in the Netherlands. The workshop runs from } \\
\text { 09:00 AM to 05:00 PM daily. As he has never been in the Netherlands before, on one of the workshop days he wants to visit another place } \\
\text { that is close to Enschede. He can only spare } 40 \text { minutes (single trip time only, excluding sightseeing) to travel and wants to know which } \\
\text { cities are reachable by train from Enschede within his time budget. }\end{array}$ \\
\hline UQ6 & $\begin{array}{l}\text { How does the reachability of station } X \text { change during the day? } \\
\text { Example: How does the travel time to Almelo de Riet change over time? }\end{array}$ \\
\hline UQ7 & $\begin{array}{c}\text { Which station(s) or network segment(s) is/are heavily-served (receive more trains) or under-served (receive less trains)? } \\
\text { Example: Which segment of the network is heavily-served: segment A or segment B? }\end{array}$ \\
\hline UQ8 & $\begin{array}{c}\text { Why does it take less time to reach station } X \text { than station } Y \text {, despite } X \text { being farther away than } \mathrm{Y} \text { in geography? } \\
\text { Example: Why does travelling by train from Enschede to Deventer Colmschate take longer than travelling from Enschede to Deventer } \\
(62 \text { minutes versus } 43 \text { minutes), even though Deventer Colmschate is closer to Enschede than Deventer (46 kilometers versus } 50 \\
\text { kilometers)? }\end{array}$ \\
\hline
\end{tabular}




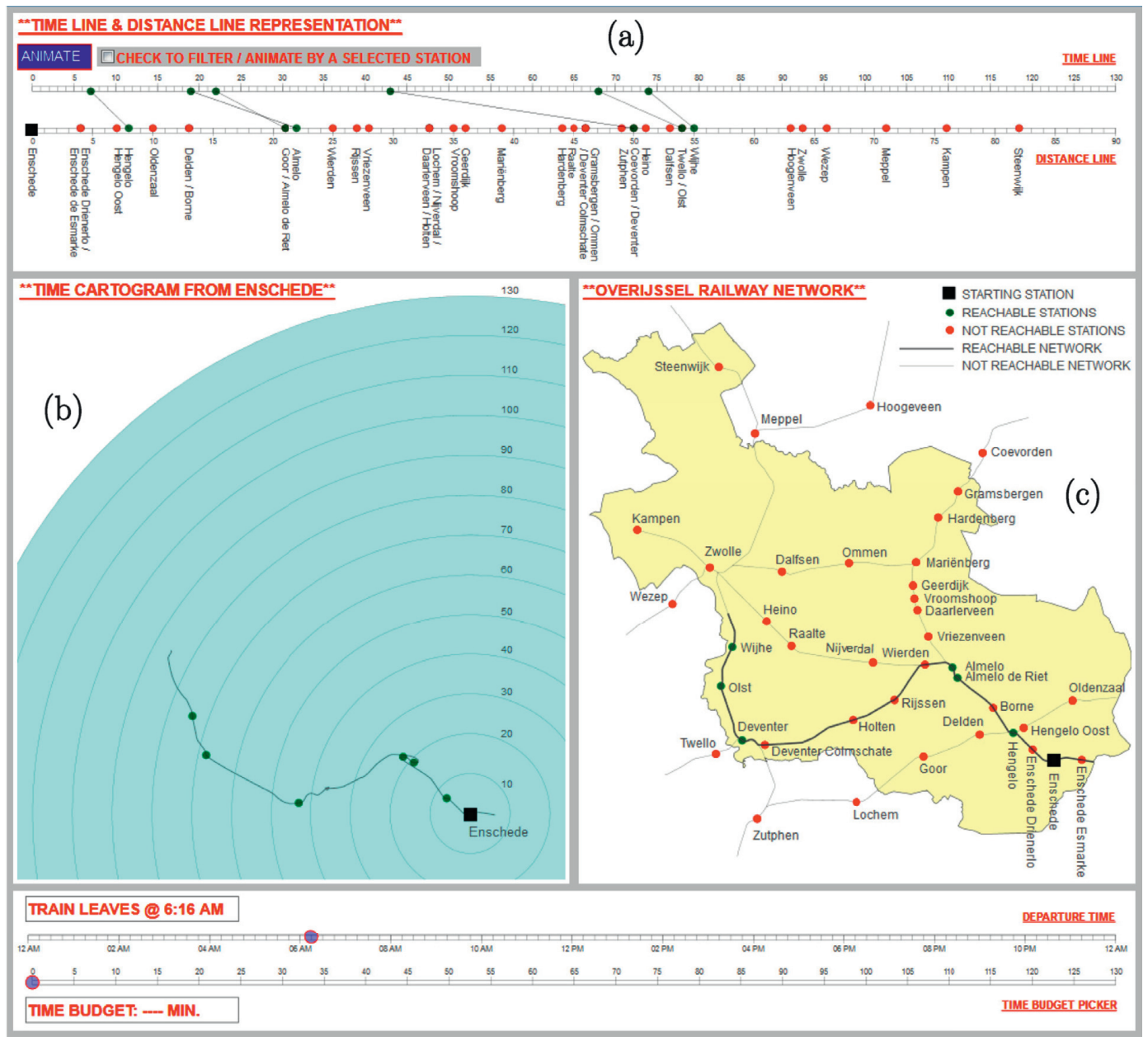

Figure 7: Travelling from Enschede with the train departing at 06:16 AM. The reachable stations are indicated by green dots, whereas those not reachable are indicated by red dots.

4.3. UQ3: Which Stations Can Be Reached within X Minutes with the Train Departing at Time T? A traveler can in some cases be interested to find out which stations are reachable within $X$ minutes with the train departing at time $T$. The numbers along the time line and the concentric circles in the time cartogram map show travel times in minutes of the reachable stations at a selected time instant. For instance, one can see that fifteen stations (namely, Enschede Drienerlo, Hengelo, Hengelo Oost, Oldenzaal, Borne, Delden, Almelo de Riet, Goor, Almelo, Wierden, Nijverdal, Lochem, Zutphen, Raalte, and Heino) are reachable within 60 minutes from Enschede with the train leaving at 06:04 AM (see Figures 4(a) and 4(b)). At 06:16 AM, only four stations (namely, Hengelo, Almelo de Riet, Almelo, and Deventer) are reachable within 60 minutes (see Figures 7(a) and 7(b)).

\subsection{UQ4: When Does It Take the Least or the Most Time to} Reach Station X during Time Interval T1-T2? The visualization environment can help an individual to figure out when it takes the most or the least time to reach station $X$ during time interval T1-T2. The time slider can be moved forward and backward to interact with the animation.
Clicking on the animate/pause button plays/stops the animation. By default, the animation runs from 12:00 AM to 11:59 PM and shows how the reachability of stations changes over time. The time slider and the animate/pause button can be used to run the animation for a particular time interval. In the graphics in Figures 4 and 8, we played the animation from 06:00 AM to 07:00 AM and the following patterns were observed. At 06:04 AM, it takes 93 minutes to reach Ommen (see Figure 4). At 06:19 AM, it takes 63 minutes to reach Ommen (see Figure 8). The geographic map and the time cartogram explain why it takes more time to reach Ommen at 06:04 AM than at 06: 19 AM. At 06:04 AM, Ommen is reachable via Zwolle, while at 06:19 AM, Ommen is reachable via Mariënberg. This also indicates that the shortest path to Ommen is travelling via Mariënberg, but it takes the longest when travelling via Zwolle.

4.5. UQ5: Given a Time Budget of X Minutes, Which Stations Can Be Reached with the First Train Departing after Time T? Sometimes travelers want to know which stations they can reach with the first train leaving after time instant $T$ 


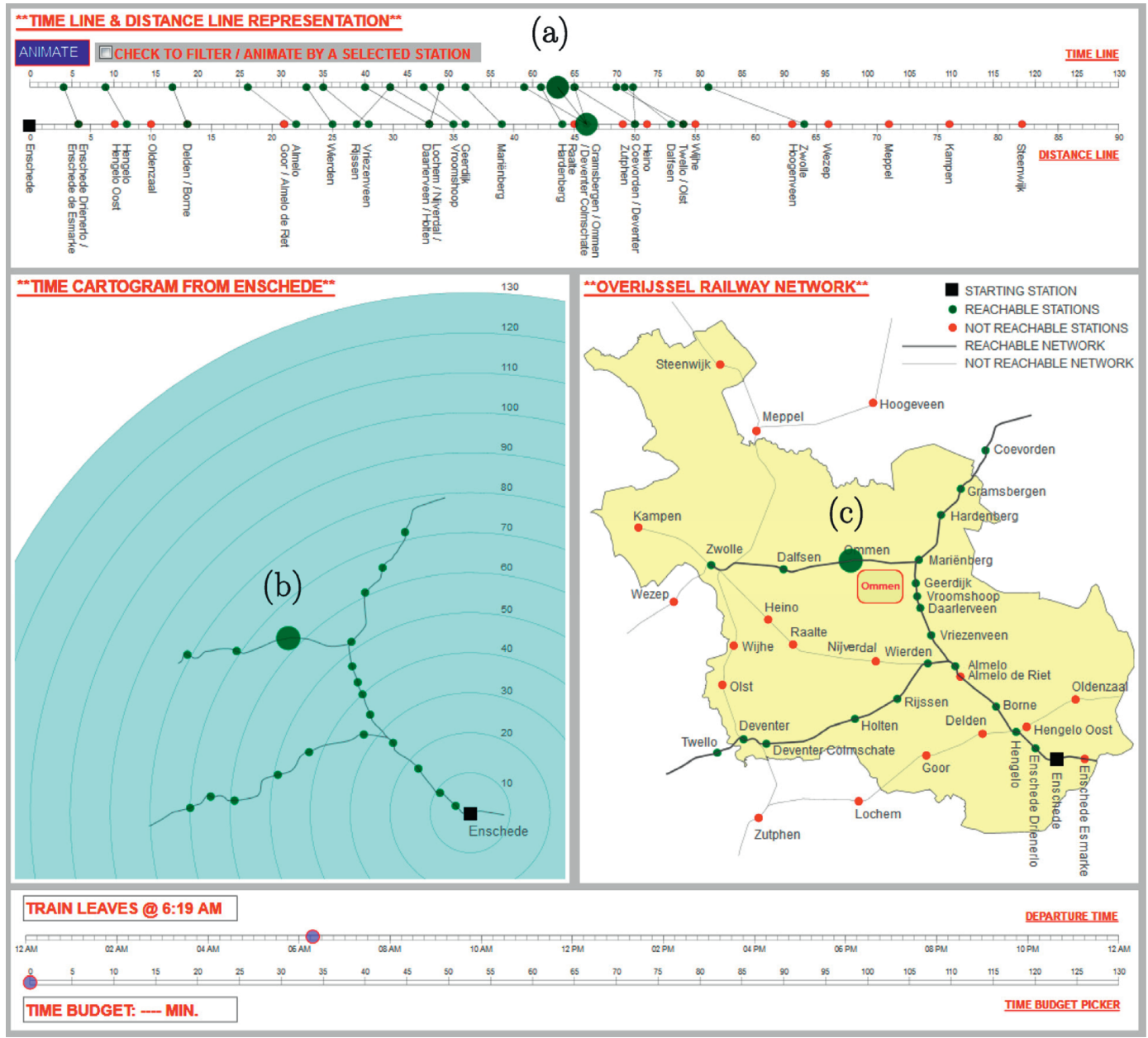

Figure 8: Travelling from Enschede at 06:19 AM. The reachable stations are indicated by green dots, whereas those not reachable are indicated by red dots. The time line and the time cartogram show that it takes 63 minutes to reach the highlighted station (Ommen) from Enschede when leaving at 06:19 AM.

provided a time budget of $X$ minutes. An example could be the following: Robert is in Enschede to attend a 3-day workshop at the University of Twente in the Netherlands. The workshop runs from 09:00 AM to 05:00 PM daily. As he has never been in the Netherlands before, on one of the workshop days he wants to visit another place that is close to Enschede. He can only spare 40 minutes to travel (single trip time only, excluding sightseeing) and wants to know the cities that are reachable by train from Enschede within his time budget. The graphics in Figures 5 and 6 explain how the visualization environment can be used to address such queries. If Robert is at the Enschede train station at 06:04 PM with no travel budget constraints, he can reach twenty-four stations (as shown on the time line in Figure 5). At 06:04 PM, but with a time budget of 40 minutes, he can reach twelve stations (Figure 6(a)). If the time budget is increased to 80 minutes, he can travel to sixteen stations (Figure 6(b)).
4.6. UQ6: How Does the Reachability of Station X Change during the Day? An individual or the transport planners might be interested in knowing how the reachability of a station $X$ changes over time. This can be investigated by selecting the filter and the desired station on the geographic map. Running the animation then shows how the reachability of the selected station changes over time. In Figure 9, the selected station is Almelo de Riet. The animation shows some interesting patterns. For instance, it takes 42 minutes to reach Almelo de Riet from Enschede at 04:45 AM and 21 minutes at 05:49 AM.

4.7. UQ7: Which Station(s) or Network Segment(s) Is/Are Heavily-Served or Under-Served? The transport planners might also be interested in knowing which stations or segments of the network are heavily-served and which are under-served. Running the animation from 12:00 AM to 


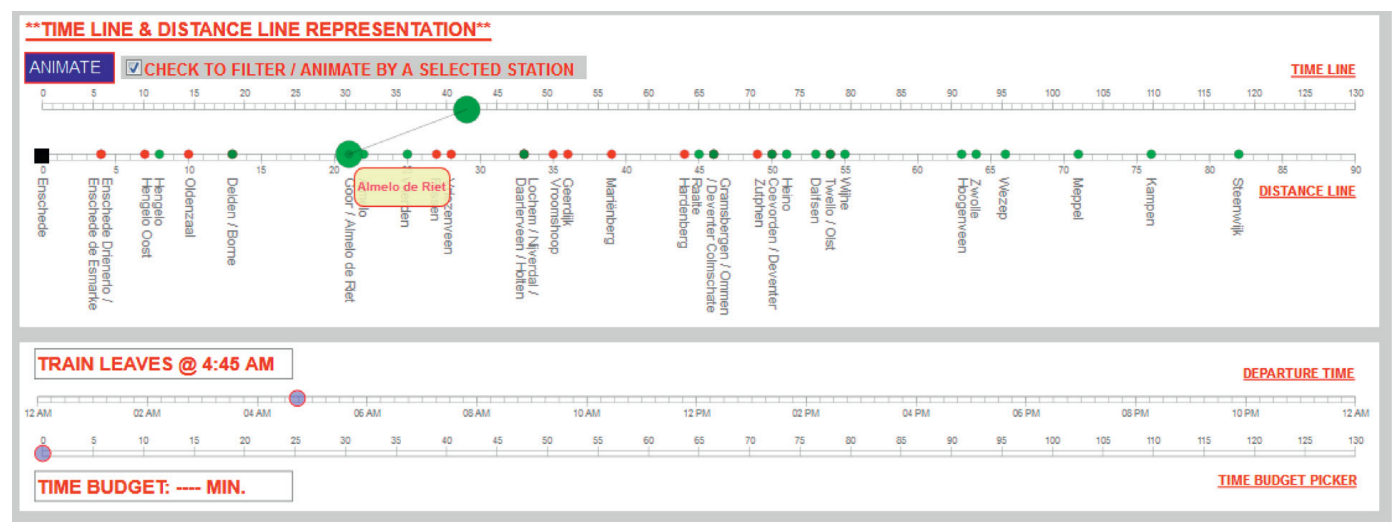

(a)

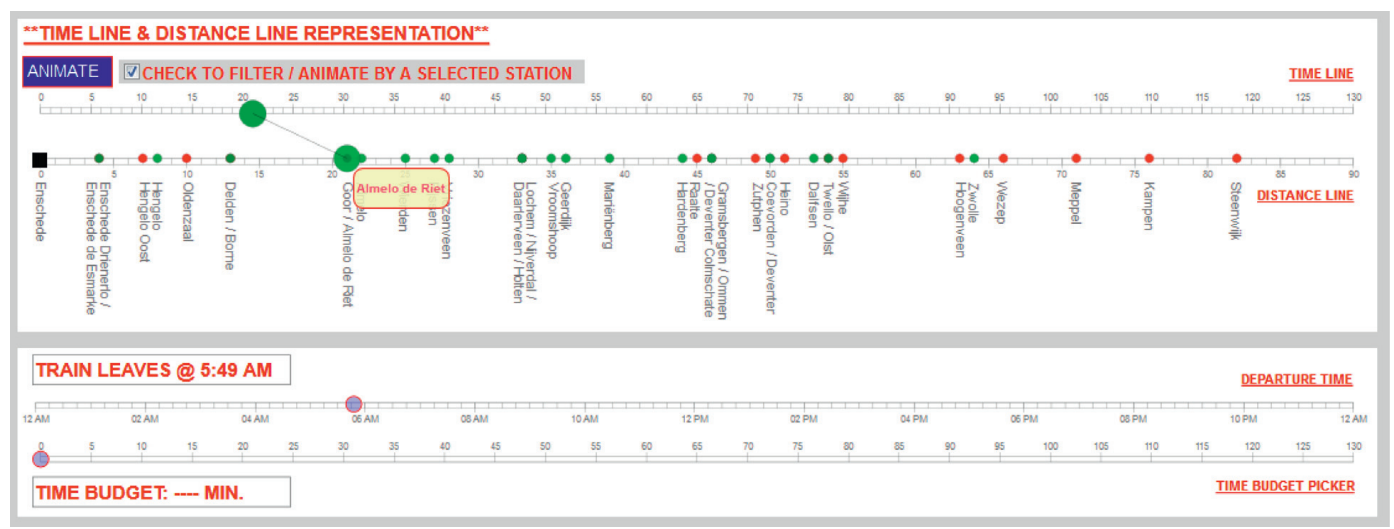

(b)

Figure 9: Travelling to Almelo de Riet from Enschede at 04:45 AM (a) and 05:49 AM (b).

11:59 PM reveals interesting findings. One can find out that the stations on the railroad segments labelled as A and $B$ in Figure 10 are under-served; i.e., a fewer number of trains travel in these directions. In addition, the travel times to these stations are longer because of the slower connections. On the other hand, all stations on the railroad segments labelled as $\mathrm{C}$ and $\mathrm{D}$ in Figure 10 are heavilyserved; i.e., more trains travel in these directions. The stations on these railroad segments have shorter travel times due to faster connections.

4.8. UQ8: Why Does It Take Less Time to Reach Station X Than Station Y, despite X Being Farther away Than Y in Geography? Sometimes a station (e.g., $X$ ) takes less travel time to reach than another station (e.g., $Y$ ), despite $X$ being farther away than $Y$ in geography. This is because of the different train types: those that stop at every station (stop trains) and those that stop only at the main stations (intercity trains). Consider Figure 11. Travelling by train from Enschede to
Deventer Colmschate takes longer time than travelling from Enschede to Deventer (62 minutes versus 43 minutes) because of slower connections, even though Deventer Colmschate is closer to Enschede than Deventer (46 kilometers versus 50 kilometers). Deventer is an intercity or main station and is served by intercity trains. On the other hand, Deventer Colmschate is a regular station and is served by stop trains. Similarly, it takes more time to reach Almelo de Riet than Almelo (41 minutes versus 19 minutes), despite Almelo de Riet being closer than Almelo in geography (21 kilometers versus 22 kilometers). This can be seen in Figure 12. Our visualization environment can be helpful for transport planners to figure out which stations take longer time to reach despite the fact that they are geographically closer and improve the connections if needed. These patterns can be discovered from the crossing lines on time line/distance line (as seen in Figures 11(a) and 12(a)) and also self-crossing railroad lines in the time cartogram (as seen in Figures 11(b) and 12(b)). 


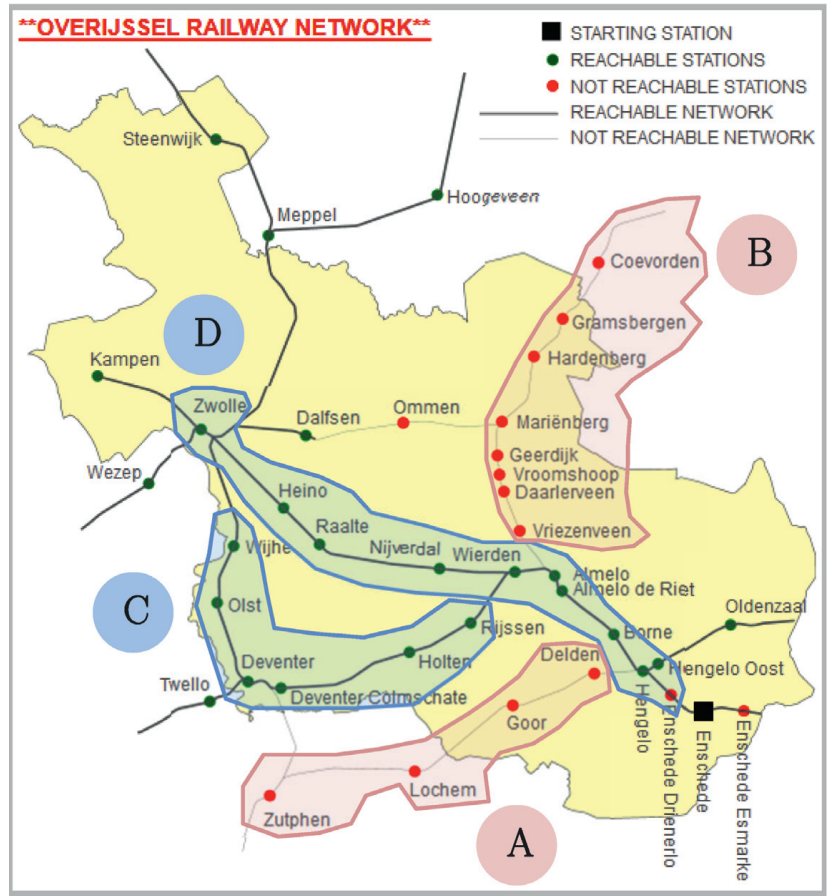

FIGURE 10: Under-served versus heavily-served stations and network segments. The stations on the railroad segments labelled as A and B are under-served, whereas the stations on the railroad segments labelled as C and D are heavily-served.

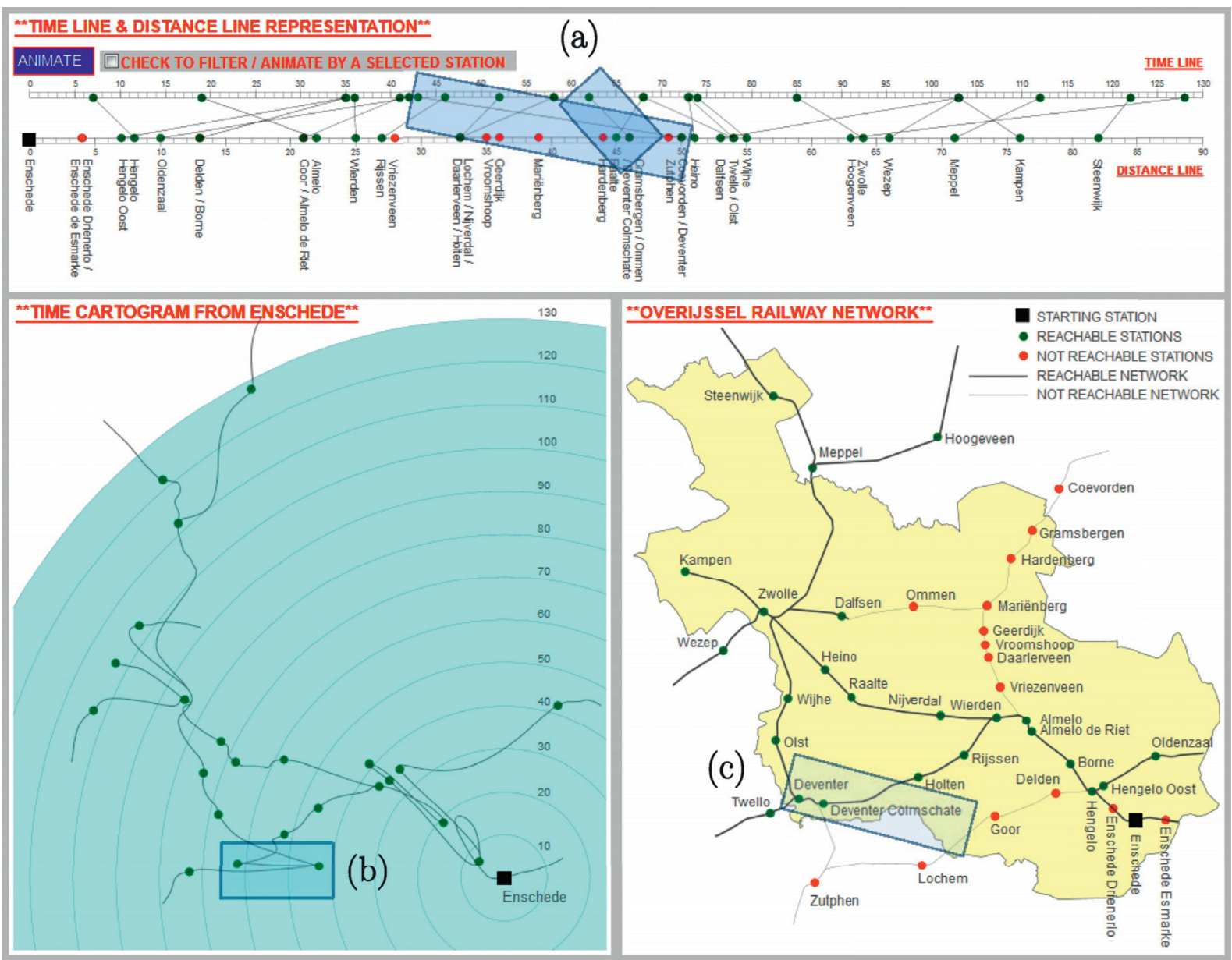

Figure 11: Travelling to Deventer and Deventer Colmschate from Enschede at 05:16 AM. 


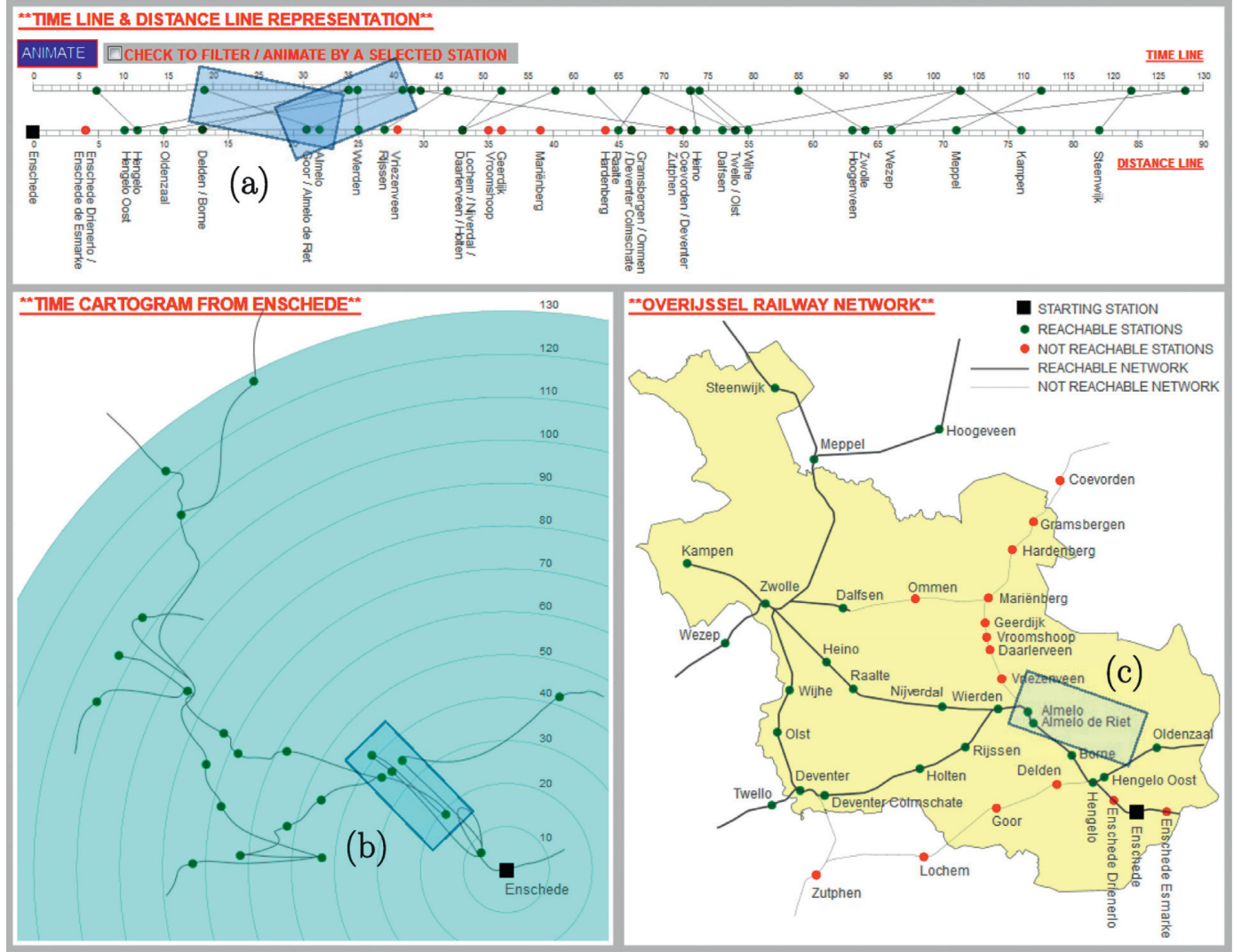

Figure 12: Travelling to Almelo and Almelo de Riet from Enschede at 05:16 AM.

\section{Conclusions and Future Work}

This research has presented the concept of a systematic, user-centric, and task-oriented visualization design framework for modelling reachability in transport networks. In the first step, a set of user questions were formulated in coordination with both frequent and casual train travelers. In the second step, the design and implementation of the visualization environment (largely influenced by the user questions and users' ease in interacting with it) were carried out to answer the questions posed by the users.

We integrated several (carto)graphic representations, the time line, the distance line, the time prism, the time cartogram, and the geographic map, in an interactive linked-views environment. A prototype was implemented in a web environment using D3.js. The implementation can be applied to any transport network. In this research, this has been achieved in the context of a large Dutch province of Overijssel with a fairly complex railroad network. This is a testament to the power and flexibility of our approach.

The approach as presented and used here provides an easily understood method for examining accessibility in transport networks. As is clear from the foregoing, the solution provides an alternative perspective for analyzing the network and gaining valuable insights. As a supplement to existing methods for visualizing travel times, our approach could be applied in areas such as spatial analysis and transport planning. The approach can also be the basis of more sophisticated analysis techniques.

In the future, we intend to perform a comprehensive usability evaluation and further develop the visualization environment so that it can be used by train travelers to plan their trips and transport planners as a visual analytical tool to analyze the transport network in a more focused manner.

\section{Data Availability}

The data that support the findings of this study are available from the first author, Rehmat Ullah (rehmatullah@uetpeshawar.edu.pk), upon reasonable request.

\section{Conflicts of Interest}

The authors declare that there are no conflicts of interest regarding the publication of this paper.

\section{Acknowledgments}

This research was supported in part by Basic Science Research Program through the National Research Foundation of Korea (NRF) funded by the Ministry of Education (no. NRF-2018R1A6A1A03025109) and by the NRF grant funded by the Korea Government (MSIT) (no. NRF2019R1A2C1006249). 


\section{References}

[1] G. Andrienko, N. Andrienko, P. Bak, D. Keim, and S. Wrobel, Visual Analytics of Movement, Springer Science \& Business Media, Berlin, Germany, 2013.

[2] G. Andrienko, N. Andrienko, J. Dykes, M.-J. Kraak, and H. Schumann, "GeoVA (t)_-geospatial visual analytics: focus on time," Journal of Location Based Services, vol. 4, no. 3-4, pp. 141-146, 2010.

[3] G. Diansheng, C. Jin, A. M. MacEachren, and K. Liao, "A visualization system for space-time and multivariate patterns (VIS-STAMP)," IEEE Transactions on Visualization and Computer Graphics, vol. 12, no. 6, pp. 1461-1474, 2006.

[4] X. Li, "The time wave in time space: a visual exploration environment for spatio-temporal data," Ph. D thesis, University of Twnete, Enschede, Netherlands, 2010.

[5] X. Li and M.-J. Kraak, "The time wave. A new method of visual exploration of geo-data in time-space," The Cartographic Journal, vol. 45, no. 3, pp. 193-200, 2008.

[6] R. Ullah and M.-J. Kraak, "An alternative method to constructing time cartograms for the visual representation of scheduled movement data," Journal of Maps, vol. 11, no. 4, pp. 674-687, 2014.

[7] S. Bies and M. van Kreveld, "Time-space maps from triangulations," in Graph Drawing, W. Didimo and M. Patrignani, Eds., pp. 511-516, Springer, Berlin, Germany, 2013.

[8] S. Hong, R. Kocielnik, Y. Min-Joon, S. Battersby, K. Juho, and C. Aragon, "Designing interactive distance cartograms to support urban travelers," in Proceedings of the 2017 IEEE Pacific Visualization Symposium (PacificVis), Seoul, Republic of Korea, April 2017.

[9] E. Shimizu and R. Inoue, "A new algorithm for distance cartogram construction," International Journal of Geographical Information Science, vol. 23, no. 11, pp. 1453-1470, 2009.

[10] R. Han, Z. Li, P. Ti, and Z. Xu, "Experimental evaluation of the usability of cartogram for representation of GlobeLand30 data," ISPRS International Journal of Geo-Information, vol. 6, no. 6, p. 180, 2017.

[11] R. Ullah, Z. Mengistu Eskedar, C. P. J. M. van Elzakker, and M.-J. Kraak, "Usability evaluation of centered time cartograms," Open Geosciences, vol. 8, p. 337, 2016.

[12] K. Buchin, A. van Goethem, M. Hoffmann, M. van Kreveld, and B. Speckmann, "Travel-time maps: linear cartograms with fixed vertex locations," in Geographic Information Science, M. Duckham, E. Pebesma, K. Stewart, and A. Frank, Eds., pp. 18-33, Springer International Publishing, Berlin, Germany, 2014.

[13] Y.-H. Wu and M.-C. Hung, "Non-connective linear cartograms for mapping traffic conditions," Cartographic Perspectives, vol. 65, pp. 33-50, 2012.

[14] T. Hägerstraand, "What about people in regional science," Papers in Regional Science, vol. 24, pp. 7-24, 1970.

[15] T. Gärling and E. Gärling, "Distance minimization in downtown pedestrian shopping," Environment and Planning A: Economy and Space, vol. 20, no. 4, pp. 547-554, 1988.

[16] J. L. Horowitz, "Travel and location behavior: state of the art and research opportunities," Transportation Research Part A: General, vol. 19, no. 5-6, pp. 441-453, 1985.

[17] U. Landau, J. N. Prashker, and B. Alpern, "Evaluation of activity constrained choice sets to shopping destination choice modelling," Transportation Research Part A: General, vol. 16, no. 3, pp. 199-207, 1982.
[18] A. Pred, "The choreography of existence: comments on Hagerstrand's time-geography and its usefulness," Economic Geography, vol. 53, no. 2, pp. 207-221, 1977.

[19] C. E. Sigal, A. A. B. Pritsker, and J. J. Solberg, "The stochastic shortest route problem," Operations Research, vol. 28, no. 5, pp. 1122-1129, 1980.

[20] H. J. Miller, "Modelling accessibility using space-time prism concepts within geographical information systems," International Journal of Geographical Information Systems, vol. 5, no. 3, pp. 287-301, 1991.

[21] H. J. Miller, Time Geography and Space-Time Prism International Encyclopedia of Geography: People, the Earth, Environment and Technology, John Wiley \& Sons, Hoboken, NJ, USA, 2016.

[22] Y. Song and H. J. Miller, "Simulating visit probability distributions within planar space-time prisms," International Journal of Geographical Information Science, vol. 28, no. 1, pp. 104-125, 2014.

[23] N. Ahmed and H. J. Miller, "Time-space transformations of geographic space for exploring, analyzing and visualizing transportation systems," Journal of Transport Geography, vol. 15, no. 1, pp. 2-17, 2007.

[24] C. Cauvin, "A systemic approach to transport accessibility. a methodology developed in strasbourg: 1982-2002," Cybergeo: European Journal of Geography, 2005.

[25] X. Chen, "Seeing differently: cartography for subjective maps based on dynamic urban data," M.Sc. thesis, Massachusetts Institute of Technology, Cambridge, MA, USA, 2011.

[26] J.-C. Denain and P. Langlois, "Cartographie en anamorphose," Mappemonde, vol. 49, no. 1, pp. 16-19, 1998.

[27] A. Goedvolk, "De nieuwe relatieve afstand voor het openbaar vervoer," Nieuwe Geografenkrant, vol. 10, pp. 6-7, 1988.

[28] C. Kaiser, F. Walsh, C. Q. Farmer, and A. Pozdnoukhov, "User-centric time-distance representation of road networks," in Geographic Information Science, S. Fabrikant, T. Reichenbacher, M. Kreveld, and C. Schlieder, Eds., pp. 85-99, Springer, Berlin, Germany, 2010.

[29] L. Ramaer, "De vervaardiging van temporele kartogrammen. 100 jaar veranderingen in de reistijd per trein in beeld," GeoInfo, vol. 11, pp. 11-13, 2011.

[30] F. Tang, A Comparative Study of Various Travel Time Representation Approaches for a Road Network, Department of Land Surveying and Geo-Informatics, The Hong Kong Polytechnic University, Yau Ma Tei, Hong Kong, 2012.

[31] M. van Campenhout, "Travel time maps," M.Sc. thesis, Technical University Eindhoven, Enschede, Netherlands, 2010 .

[32] W. Aigner, S. Miksch, W. Müller, H. Schumann, and C. Tominski, "Visualizing time-oriented data-a systematic view," Computers \& Graphics, vol. 31, no. 3, pp. 401-409, 2007.

[33] A. Kölzsch, A. Slingsby, J. Wood, B. Nolet, and J. Dykes, "Visualisation design for representing bird migration tracks in time and space," in Proceedings of the 2013 Workshop on Visualisation in Environmental Sciences (EnvirVis), Leipzig, Germany, July 2013.

[34] J. I. Maletic, A. Marcus, and M. L. Collard, "A task oriented view of software visualization," in Proceedings of the Visualizing Software for Understanding and Analysis First International Workshop, Paris, France, June 2002.

[35] M. Schots and C. Werner, "Using a task-oriented framework to characterize visualization approaches," in Proceedings of the 2014 Second IEEE Working Conference on Software Visualization (VISSOFT), Victoria, Canada, February 2014. 
[36] M.-J. Kraak, B. Köbben, and Y. Tong, "Integrated time and distance line cartogram: a schematic approach to understand the narrative of movements," Cartographic Perspectives, vol. 77, pp. 7-16, 2014.

[37] D. A. Keim, J. Kohlhammer, G. Ellis, and F. Mansmann, Mastering the Information Age-Solving Problems with Visual Analytics, Eurographics Association, Norrköping, Sweden, 2010.

[38] J. Dykes, A. M. MacEachren, and M. J. Kraak, Exploring Geovisualization, Elsevier, Amsterdam, Netherlands, 2005.

[39] M.-J. Kraak, “Timelines, temporal resolution, temporal zoom and time geography," in Proceedings of the 22nd International Cartographic Conference, A Coruña, Spain, December 2005.

[40] J. C. Roberts, "Exploratory visualization with multiple linked views," in Exploring Geovisualization, J. Dykes, A. M. MacEachren, and M.-J. Kraak, Eds., pp. 159-180, Elsevier, Amsterdam, Netherlands, 2005.

[41] M. Bostock, V. Ogievetsky, and J. Heer, " $\mathrm{D}^{3}$ data-driven documents," IEEE Transactions on Visualization and Computer Graphics, vol. 17, no. 12, pp. 2301-2309, 2011.

[42] B. Köbben, "Towards a national atlas of The Netherlands as part of the national spatial data infrastructure," The Cartographic Journal, vol. 50, no. 3, pp. 225-231, 2013. 